\title{
Notiz über das Verhalten des Phtalids bei der Destillation mit Kalk
}

\author{
von \\ Hans Krczmař.
}

Aus dem chemischen Laboratorium der k. $k$. deutschen Universität in Prag.

(Vorgelegt in der Sitzung am 14. Juli 1898.)

Phtalid wurde mit der dreifachen Menge reinen, ausgeglühten Kalkes gemengt, in einem Glasrohre, durch das ein langsamer Wasserstoffstrom geleitet wurde, erhitzt. Die Temperatur wurde zunächst so niedrig wie möglich gehalten, sie war nicht höher als eben nothwendig, um das Phtalid zu destilliren, dessen Siedepunkt bei $290^{\circ}$ liegt.

Es ging eine Flüssigkeit über, die, zunächst wasserhell, gegen das Ende der Destillation, wo die Temperatur etwas gesteigert wurde, eine bräunlichgelbe Färbung annahm.

In das vordere, weniger erhitzte Ende der Röhre sublimirte eine gelbe krystallinische Masse, die durch Erhitzen aus dem Rohre herausdestillirt und besonders aufgefangen wurde.

Im Rohre selbst waren nur geringe Anzeichen von Verkohlung zu sehen.

Das flüssige Destillationsproduct wurde fractionirt, wobei eine wasserhelle Flüssigkeit zwischen 81 und $110^{\circ}$ überging und im Fractionskölbchen eine gelbbraune Masse zurückblieb.

Auf diese Weise waren aus $35 g$ Phtalid $17 g$ flüssiges und $2 g$ festes Destillat erhalten worden.

Der flüssige Antheil wurde nun fractionirt, wobei die Hauptmenge (circa zwei Drittel) zwischen 81 und $83^{\circ}$ überging. Der Rest wurde in Fractionen, die von $84-95^{\circ}$ und von 95 bis $110^{\circ}$ übergingen, aufgefangen. 
Der bei $83^{\circ}$ siedende Antheil erstarrte bei Eiskühlung und gab bei Behandlung mit Salpeter-Schwefelsäure Nitrobenzol, ist somit als Benzol identificirt worden.

Die Fraction 95-110 wurde behufs des Nachweises von eventuell vorhandenem Toluol mit Chromsäure oxydirt. Die Anwesenheit einer sehr geringen Menge Benzoësäure konnte nur durch den Geruch constatirt werden; ein Isoliren der Säure war in Anbetracht der äusserst geringen Menge derselben nicht möglich.

Das feste Destillationsproduct wurde nochmals destillirt und zeigte nach dem Umkrystallisiren aus Alkohol den Schmelzpunkt $211^{\circ}$.

Da zu erwarten war, dass sich bei der Destillation des Phtalids mit Kalk hochmoleculare Kohlenwasserstoffe, wie Phenanthren, Anthracen oder Stilben, bilden könnten, so lag es nahe, den so erhaltenen Körper für Anthracen zu halten.

Um dies festzustellen, wurde er nach den Angaben von Claus ${ }^{1}$ in heisser alkoholischer Lösung mit Brom behandelt, wobei sich beim Erkalten ein Körper ausschied, der den Schmelzpunkt $274^{\circ}$ zeigte und sich als Anthrachinon erwies.

Dadurch war die Identität des Destillationsproductes als Anthracen festgestellt.

An dem Geruche desselben glaube ich die Anwesenheit geringer Mengen Diphenyl erkannt zu haben.

Was die Reaction bei dieser Behandlung des Phtalids anbelangt, so dürfte dieselbe in der Weise vor sich gehen, dass $\mathrm{CO}_{2}$ abgespalten und unter Austritt von Wasserstoff eine Aneinanderlagerung der Reste eintritt, wodurch das Auftreten von Anthracen seine Erklärung findet.

Die Bildung des Benzols ist schwerer zu erklären. Toluol hätte allenfalis auftreten können: dasselbe gibt zwar beim Durchleiten durch ein in heller Rothgluth befindliches Rohr Benzol; eine solche Bedingung war aber nicht vorhanden, da, wie schon oben erwähnt, die Temperatur, bei der die Destillation vorgenommen wurde, unter Rothgluth lag.

\footnotetext{
1 B. 10,926 .
} 